\title{
Damage to an overpass bridge from WBS prefab beams
}

\author{
Kazimierz Furtak ${ }^{1, *}$, and Mariusz Hebda ${ }^{1}$ \\ ${ }^{1}$ Politechnika Krakowska, ul. Warszawska 24, 31-155 Kraków, Polska
}

\begin{abstract}
The article presents a description and analysis of the causes of damage to a road viaduct, made of prefabricated compressed beams of the WBS type in the 1970s. Both the design and damage are typical for objects made in those years. Damage results from the deck slab being too thin, low quality waterproof membrane, easily deformable deck surface, leaking bridge deck expansion joints, linear-contact bearings at excessively long spans, undurable drainage system elements. On the basis of the static and strength analysis, proposals for a way of repairing the viaduct were given, which, taking into account the occurrence of similar structural solutions in existing facilities, can be used as a guide when designing renovation and modernization.
\end{abstract}

\section{Introduction}

The development of motorization and road transport in Poland in the 1970's demanded the construction of many kilometres of roads and new bridge structures. The businesses operating on the Polish market were not prepared to build such a huge number of bridges, viaducts and flyovers adopting the previously used methods. Prefabrication was seen as the solution to the problems. Several types of beams rather than entire systems were proposed. WBS prestressed beams were one of the beam types used at the time.

After some years it was found that many structures had suffered similar damage. The damage was mainly caused by the use of too thin $(12 \mathrm{~cm})$ deck slab, low quality waterproof membrane, easily deformable deck surface, leaking bridge deck expansion joints, linearcontact bearings at excessively long spans, concrete kerbs, short-lived drainage system elements. All these factors were found in the structure under consideration. In this case the damage was strongly affected by the poor quality of work resulting from time pressure, among other things.

Moreover, a large part of the repair works performed several times were also done inadequately, which is why the repair activities were not effective enough. Further degradation of the structure continued. Its state required an in-depth analysis. The paper presents the results of this analysis together with recommended modifications of construction solutions as well as expected effects of the proposed activities.

\footnotetext{
*Corresponding author : kfurtak@pk.edu.pl
} 


\section{Analysis of the structures}

The object analysed is a single span flyover bridge located in the course of a national road, above a railway line and a motorway. Its original structural arrangement consisted of five quasi-frames of the spans number $2+2+3+2+2=11$. Following one of the first repair works the first two and the last two quasi-frames were provided continuity thus creating a $4+3+4$ arrangement. The continuation of the spans above the piers was done via the deck slab only. The piers bearings system was characteristic of simply supported spans; also on those pillars over which the continuation was executed. The general view of the object is shown in Fig. 1.

The load carrying structure of the flyover was a composite structure of WBS prestressed beams and RC deck. The three central spans were made of beams of $20.20 \mathrm{~m}$ (axial distance of supports $22.26 \mathrm{~m}$ ), outer spans from beams of $19.00 \mathrm{~m}$, while the other spans from beams of $18.00 \mathrm{~m}$ (axial distance of supports $20.00 \mathrm{~m}$ ). The longer spans $(5 \div 7)$ had fifteen beams each in cross-section, the shorter spans $(1 \div 4$ and $8 \div 11) 12$ beams each. The layout of the beams in the cross section was such that cantilever's overhangs in all the spans were equal, regardless of the span length and the number of beams in the cross-section.

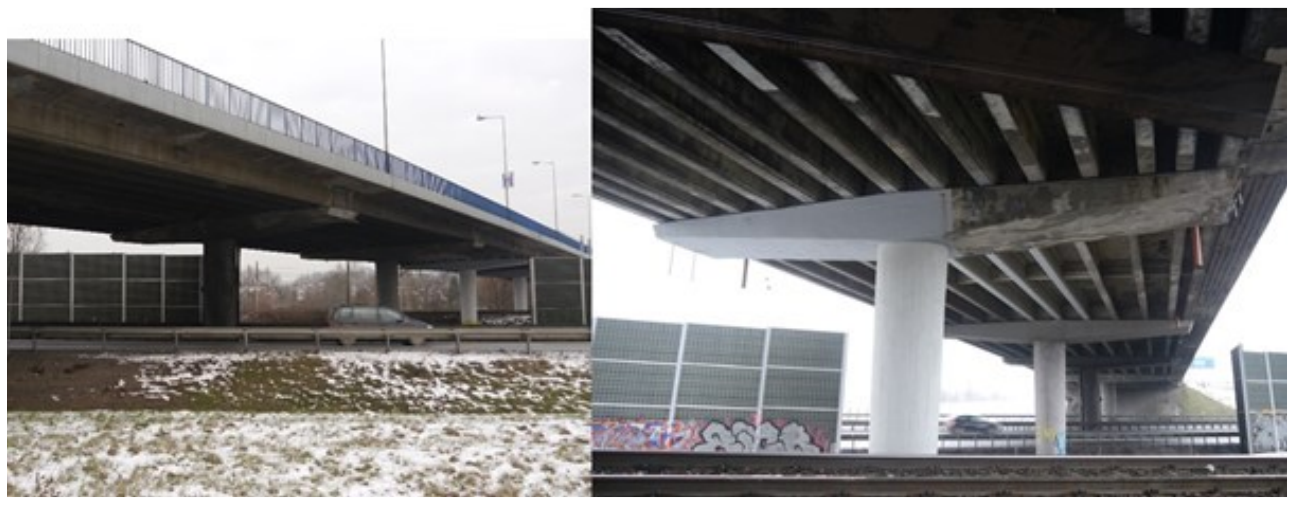

Fig. 1. General view of the flyover bridge.

The net length of the spans is: $19,00+3 \times 20.00+3 \times 22.26+3 \times 20.00+19.00=$ $=224.78 \mathrm{~m}$, and the overall length of the object (together with abutments and wing walls) $234.00 \mathrm{~m}$. The object's overall width is: $1.18+0.36+0.50+14.00+0.50+0.36+1.18=$ $=18.08 \mathrm{~m}$. The width covers a four-lane roadway $4 \times 3.50=14.00 \mathrm{~m}$ wide, footways on each side $1.18 \mathrm{~m}$ each, safety barriers and lanes separating the barriers from the roadway of $0.36 \mathrm{~m}$ and $0.50 \mathrm{~m}$, respectively. Except the beams, the other structural elements of the spans, that is the deck slab, overhang brackets and crossbeams, were made in-situ. The deck slab was originally $0.12 \mathrm{~m}$ thick. In each span three crossbeams were used - two support and one span beams. In the original design the nominal thickness of the slab was $0.12 \mathrm{~m}$. During the repair works the thickness was increased by $0.04 \square 0.06 \mathrm{~m}$. Besides, precast cornice beams were used (which increased the loading of the beams, the outer ones in particular).

All the piers of the flyover are columns of circular cross section. The diameter of the higher columns decreases upwards. However, in the cross section of the connection with the cap beam cantilevers they all have the diameter of $2.00 \mathrm{~m}$. Founded on RC piles, topped with continuous footing. The pier cap beams on column tops are double cantilevered of trapezoidal cross-section. Standard fittings typical of this type of objects, including:

- the roadway surface made of asphalt concrete,

- footways with chemically cured resin lining,

- kerbs,

- bituminous expansion joints above abutments and piers no. 5 and 8 , 
- parapets (P-1 $1.10 \mathrm{~m}$ high),

- SP-06 safety barriers,

- lamp posts,

- drainage elements,

- polymer concrete cornice board.

What was critical for the bridge's life were leaking expansion joints and waterproof membrane. The bridge is located on a straight section of the road of a vertical curve profile of the radius of $500 \mathrm{~m}$. The cross slope is $2 \%$ (outwards). The longitudinal slope is variable (owing to the vertical curve) but sufficient for gravitational surface drainage (provided the road surface is even).

\section{Assessment of the state of the bridge and its historical conditions}

A review of the hitherto executed repair works is necessary for the assessment of their effectiveness and the structural modifications applied. The object in question was placed in service in 1974. From the very beginning its construction was carried out under pressure of time and the quality of work was poor, especially in the final stage, mainly when the fittings were performed. The haste in the final phase of the construction was dictated by the desire to have it completed by July 22, the Polish Revival Day. Hence the errors and faulty execution, together with the low quality of the materials (except the concrete of the beams) and components.

Already during the beams assembly local exposure of beams stirrups was noticed, which indicated too thin coating and inaccurately produced prefabricated elements. However, no decision to interrupt the works or replace the beams that did not satisfy the quality criteria was taken. It was unfortunate that the coating was not repaired at the spots of exposed stirrups. The same can be said about the scope and quality of the repair works performed several times during the operation of the bridge.

The deck slab $0.12 \mathrm{~m}$ thick complied with the standards valid at the time. This thickness of deck slab was used in many other objects from WBS beams. Similar problems were observed in these objects. In the bridge under consideration holes appeared in some spans (as in other objects). Another problem that was reported in thin slabs - and in the analysed structure it was aggravated by the inaccuracies of execution (poor quality) and haste - were considerable deviations of the location of the upper and lower mesh reinforcement from that stipulated in the design. Lowering the lower mesh reinforcement resulted in insufficient coating thickness at the bottom of the slab, while lowering the upper mesh reinforcement reduced the arm of the internal forces. In the former case, it decreased the durability, in the latter case it decreased the load capacity (especially in the sections above the beams).

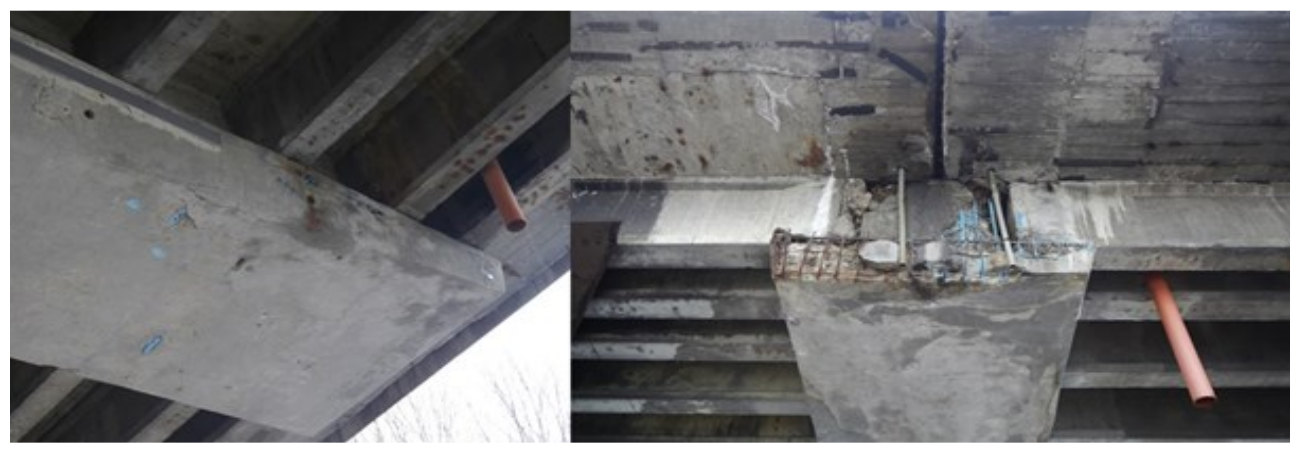

Fig. 2. Technical state of some elements of the flyover bridge. 
Similar problems were exacerbated by incorrect technology of waterproof membrane installation (independent of the material quality itself). Owing to the haste, the membrane was placed several days after the slab concrete was cast. The requirement for membrane placement on dry (and smooth) base was not satisfied.

The insufficient thickness of the slab, inaccuracy in reinforcement height arrangement and faulty installation of the waterproof membrane caused slab cracking and water leaking through the membrane. The water caused the contamination and destruction of the concrete. The highest intensity of destruction was reported in the spans in the direction of Kraków. During the repair works in 1987 the most corroded parts of the deck slab were removed, and next the slab was thickened by $4 \div 6 \mathrm{~cm}$.

During the same repair works the expansion joints above supports 3 and 10 were eliminated, which changed the structural scheme. However, leaking expansion joints were used (common solution at the time), and they were mounted at the deck slab level, and next covered with a bituminous surface layer. This surface was cracked above the expansions joints (not only there), which facilitated water drainage into the joints and further to the beams front and pier caps, causing their erosion and destruction.

During the waterproof membrane placement on the reconstructed deck slab the same mistake was made as when the membrane was installed during the object's construction in 1974, namely, it was placed on the wet base. The effects were similar. It can also be noted that the repair works were carried out by a company unqualified for this job. Again the works were executed under pressure of time.

Another repair of the bridge was done in 1997. It included strengthening of the abutment cap on the side from Kraków. The strengthening was achieved by the application of composite carbon fibre straps and thickening (increasing the width) of the crossbeam. In this way the stiffness of the crossbeam was improved, which partially relieved the capping beam in the transfer of operation induced loads. The losses in concrete were filled in with PCC materials. Additionally, pedestals, which were in a poor technical state, were strengthened, and the bearings were cleaned and provided corrosion protection.

These works were done solidly. But the continued durability of the bridge depended on works that had not been done (probably due to the lack of financial means), for example, the leaking waterproof membrane was not replaced, the cracked surface was not repaired. The bituminous expansion joints did not stand the test of time. They suffered cracking, which added to the leaking waterproof membrane, resulted in the corrosion of concrete and rebars in the deck slab.

The effect of the successive destruction of the structure was a poor technical condition, which was inventoried in 2010. The unsatisfactory technical condition covered a major part of the bridge. The roadway surface was deformed and cracked on its entire length. Deformation and cracking was also reported on the surface of both footways.

The waterproof membrane was leaking practically on the entire object. The poor technical condition of the membrane and surfaces resulted in further degradation of the RC deck slab. It was reported on the slab bottom in the form of extensive moisture areas and advanced corrosion of concrete and rebars.

Advanced corrosion of beams' ends was reported. The coating came off along considerable lengths of several beams. Not only the stirrups but also, in some places, the prestressing cables were exposed. The coating was loosened on large areas of pier caps. In these places surface corrosion of rebars was observed.

The object's fittings were found in a poor technical state locally. The parapets and safety barriers were corroded and deformed locally. They did not perform their functions, and drainage system elements were corroded. The cornice boards fixing raised doubts. Already at that time the bridge should have been given a radical overhaul or even reconstructed. 
During the repair works in 2012 holes appeared in three spots of the deck slab. On the basis of an in-depth analysis of the condition of the slab recommendations for repair works scope were formulated. Three separate areas were distinguished. One area covered the deck slab parts that satisfied the criteria of load carrying, durability and technical state. The next area covered the parts where under the waterproof membrane there was an asphalt concrete layer that coincided in level with the upper surface to the increased thickness of the deck slab in the spans in which it was strengthened. The third area covered the parts in which the deck slab did not meet the load carrying and durability criteria.

In the first case, no changes in the slab were recommended, in the second case the asphalt concrete layer was to be dismounted and replaced with a reinforced concrete layer. In the third case the deck slab was to be dismounted. Following these recommendations the repair on the deck slab was executed in 2012.

The inspection carried out in June 2018 showed further degradation of the object. New concrete losses and cracking were reported. They are dangerous because they are hazardous to the safe performance of the bridge as they concern prestressed beams and capping beams. While the condition of the beams does not pose a threat of catastrophe, the condition of the cantilevers of some capping beams does pose a threat of catastrophe; especially because the pedestals are partly corroded.

The poor technical state of some elements of the flyover bridge are shown in Fig. 2.

\section{Analysis of causes}

The object was put in service in 1974. It was opened in haste on July 22, the day of the Polish Revival Day celebrations. The haste resulted in poor quality of the execution works, especially the finishing and fittings, among other things. The scope of analysis focused on footways filling and elements of fittings such as waterproof membrane and roadway surface as well as the use of leaky expansion joints. The effect was rapid deterioration of the technical condition and the necessity to carry out the first repairs as soon as after several year operation of the bridge.

The poor state of object's parts partly resulted from inadequate design solutions of the deck slab and expansion joints in particular, although it has to be admitted that such solutions were widely adopted at the time in the construction of bridges from WBS beams. The effect of these unfavourable solutions on the poor state of some elements was independent of the defects resulting from the haste and poor quality of the works.

The assessment of the object's technical condition is best done by grouping the elements into categories. The support columns do not give cause for concern. There are no cracking or concrete losses. No corrosion of rebars was reported. There are no symptoms of load carrying insufficiency. This state was verified also by the structural and strength calculations.

What poses a problem -and a serious one- are pier cap beams. Their poor technical condition results from two causes. One was the leaking expansion joints, the other one was that cap beams ends protruded beyond the overhang brackets in the original design. In the former case the water leaking through the expansion joints caused the corrosion of concrete and reinforcement, in the latter one the cap beams got wet causing similar corrosion effects.

Previously, cracking of the cap beam of one of the abutments as well as cracks on the side and upper surfaces were reported. A detailed analysis showed that the cracks on the side surface appeared after the structure was provided continuity and stresses induced by temperature oscillations increased. The cracks on the upper surface were caused by spans being extra loaded with an additional RC layer. The cap beam was strengthened with composite carbon fibre straps (the second case of the application of straps for bridge strengthening in Poland). Following the calculations, two straps were glued to the side 
surface and four straps to the upper surface. After over twenty-year operation of the bridge no symptoms of overload were reported.

\section{Structural and strength analysis}

The structural and strength analysis was done for the structure's part, of the longest span of 3 x 22,60 m. Two numerical models developed with Autodesk Robot Structural Analysis were used. The first model represented the structural system in the existing state, in which on each pier on separate bearings the beams rested on each side of the span. The other model covered the proposed structural modifications, including complete (not only via the deck slab) continuity of the beams above the supports (piers) and resting them on a single bearing, centrally in the pier axis. A general view of the model of the current state of the structure is shown in Fig. 3.

In both one- and two-dimensional elements models in 3D space were used. The onedimensional elements were used for modelling the pier columns, the beams together with the composite RC slab and crossbeams, while the two-dimensional elements (coats) were used for modelling the pier cap beams. The real stiffness of individual elements of the structure was taken into account.

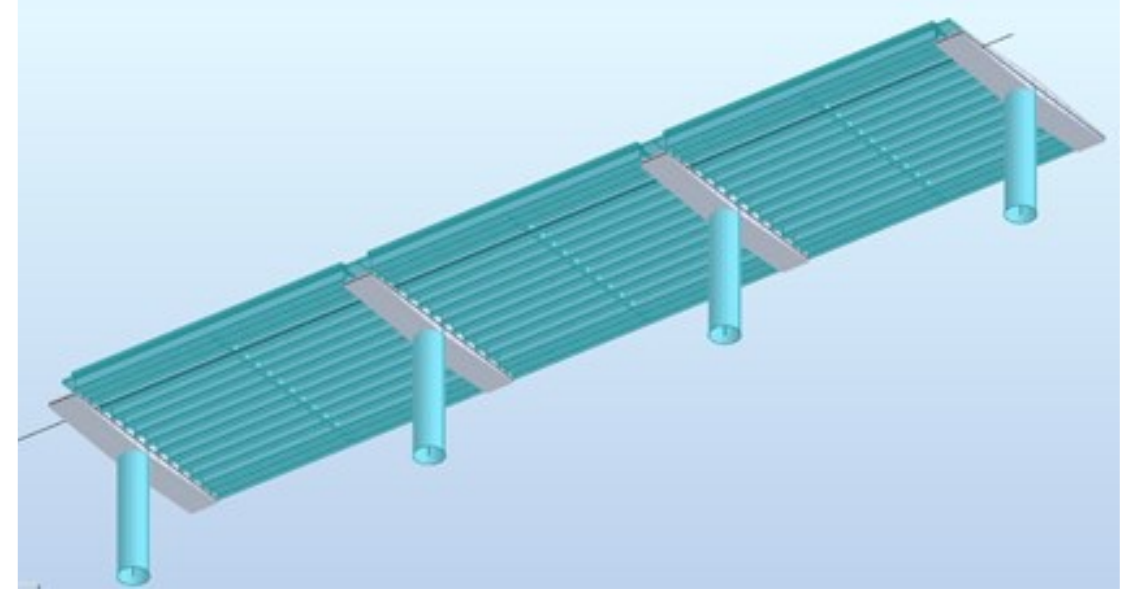

Fig. 3. A general view of the model of the current state of the structure.

The existing bearing capacity of the structure was defined by the comparison of the crosssectional forces obtained from loads after the Standard [1], valid when the flyover bridge was designed, with the forces from loads after the Standard [2]. On this basis it was found that the load bearing of all the elements of the structure, i.e. supports, WBS beams and deck slab corresponds to load class $\mathrm{C}$ after [2]. In the numerical model the beams stiffness was not reduced because of their damage (concrete losses and the corrosion of ordinary and prestressing steels). Only in the analysis of the load bearing of the beams prestressing force decrease due to the corrosion of the prestressing cables was taken into account.

A separate analysis was performed on the impact of stiffening the beams at support on relieving the pier cap beams from operational loads. In the existing state, in the support zone the beams are connected on their front with a closing wall, which, since there are no connectors fixed to the beams, does not fulfil its function of a rigid crossbeam. Therefore it was assumed in the model that the crosswise interaction of beams is provided only by the deck slab. For such assumptions, in the place of the cap beam resting on the pier a bending moment from operational loads for class $\mathrm{C}$ with a dynamic coefficient was determined. Next, a crossbeam at the bearing place was assumed, $1.20 \mathrm{~m}$ high (overall height of the beam 
together with the slab) and $1.00 \mathrm{~m}$ wide, which reduced the value of the bending moment from operational loads by $14.1 \%$.

The bending moment was reduced even more in the second model, in which a shared crossbeam $2.50 \mathrm{~m}$ wide connects, above the support, the beams of the neighbouring spans, and the rest is positioned axially on the pier. The bending moment from operational loads in the cap beam is then reduced by $19,7 \%$. It should be added that in the latter case there is a reduction of the torsional moment in the cap beam, from the reaction transferred through the bearings on both its edges, which additionally reduces its effort.

\section{Proposed modifications of structural solutions}

The main proposed structural modification of the object under consideration is the change of resting the spans on the pier cap beams. The present structural arrangement of the object is proposed to be left unchanged, that is the division into three separate parts (spans $4+3+4$ ). Another proposal concerns providing the continuity by means of crossbeams bonded with WBS beams on the entire depth. The crossbeams above the piers, where there are expansion joints, should be adopted for beams of each pier separately, at the same time shifting the position of span rest towards the joint centre line (and the centre line of the cap beam). Above the other piers crossbeams common for both spans were proposed as well as a single row of bearings in the centre line of the pier and cap beam. A scheme of the proposed structural modifications together with the existing solution is shown in Fig. 4.
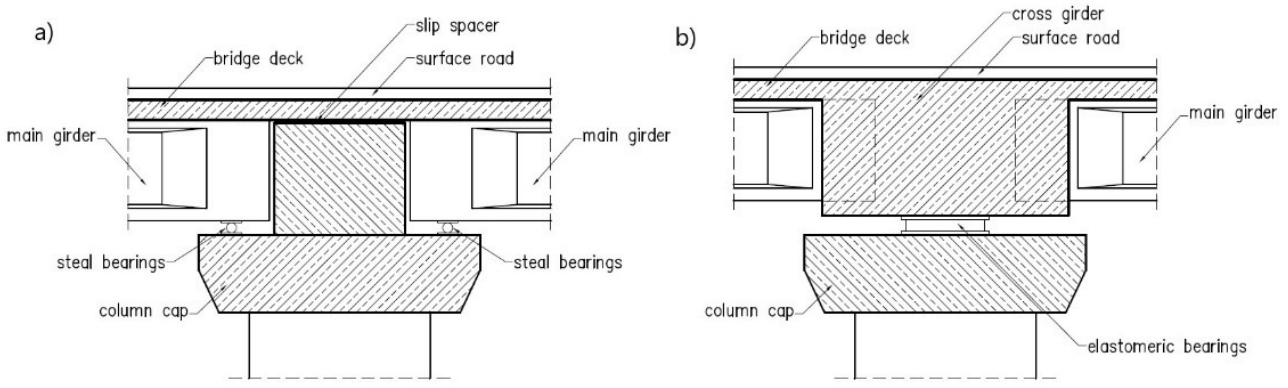

Fig. 4. Longitudinal section of the rest position on the pier: a) state at present, b) proposed change.

The presented manner of span support on the cap beam will improve its strength performance by reducing the bending moment from operational loads (cf. part 5). Moreover, it will enable the execution of more durable and efficiently operating expansion joints. The latter structural operation will result in elimination of one of the main causes of the poor technical condition of the bridge, its support and beams bearing zone in particular as the beams concrete corrosion was caused by water draining through leaking movable joints. 


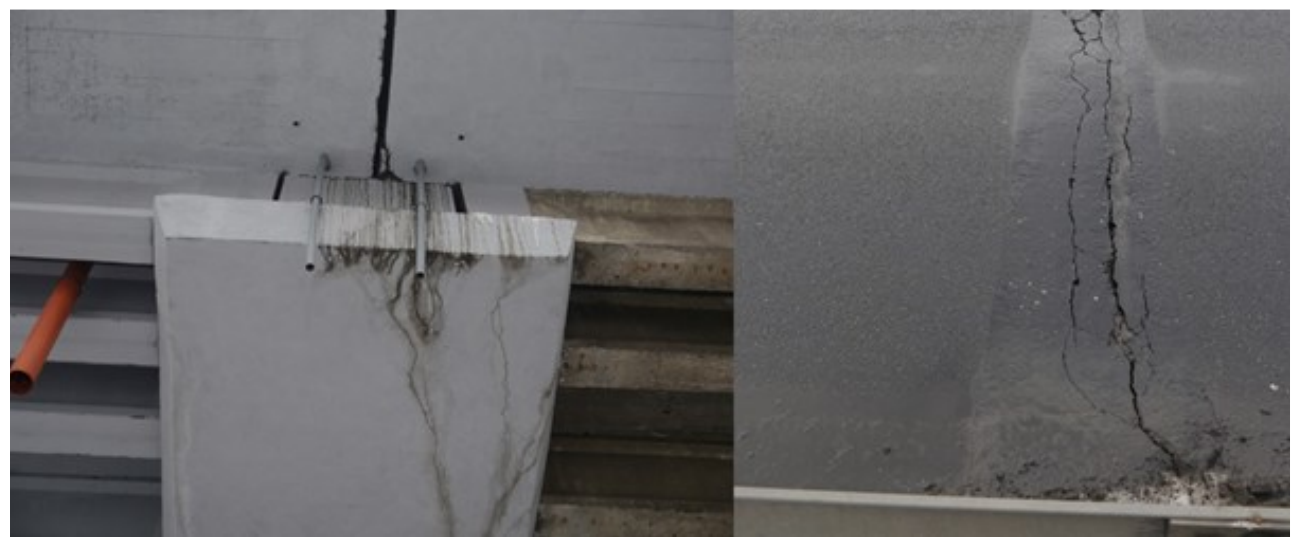

Fig. 5. Intermediate expansion joint on the flyover bridge and its damage.

The manner of beams support on the cap beam in the existing structure (and in many similar objects) is very unfavourable. The beams of two adjacent spans are based on the cap beam edge, at a considerable distance from the movable joint centre line (Fig. 5), which necessitates the location of the joint device on the cantilevered deck slab. Since the overhanging slab is not very stiff, the movable joint device is exposed to detrimental dynamic effects caused by the moving vehicles. Moreover, the beam's rotation on the bearing may cause vertical displacements (about $10 \mathrm{~mm}$ from operational loads) hazardous to the durability of the movable joint (bituminous especially). Owing to the proposed modifications the support axis can be situated closer to the movable joint centre line, thus eliminating the problem.

No other structural modifications were proposed. In particular, in view of the span design type, its age and material damage caused by corrosion, strengthening the structure to increase its load carrying was not recommended. After the structural modifications of the crossbeams and bearing system have been implemented, the load bearing of the bridge will comply with that stipulated in the design.

Apart from the presented structural modifications, it is necessary to perform repair of the primary bearing elements. The repair works should include the reconstruction of the deck slab, filling in the concrete losses, injection of cracks and fractures of pier cap beams and WBS beams, anticorrosion coating of concrete surfaces as well as replacement of fittings elements (waterproof membrane, movable joints, cornice boards, kerbs and roadway surface). As the parapets and safety barriers are in good technical state, they can be utilised in the reconstruction of the object. 


\section{Remarks and final conclusions}

The analysed object belongs to typical structural solutions applied in flyover bridges constructed in the 1970's and 1980's. Unfortunately, the damage and its causes are also typical. The most significant ones include defective solutions such as insufficient crosswise bracing of beams on support, basing adjacent spans on separate bearing systems on individual piers, a large number and faulty structural solutions of expansion joints (also their leaking in the initial stage of operation), as well as poor quality of materials and construction works.

The proposed repair scheme discussed in the paper consists in bracing the crossbeams on supports, providing continuity to spans on the entire structural depths and basing the spans on a single row of bearings in the cap beam centre line. The proposed solution seems adequate for repairs of this type of structures, particularly when the developer cannot afford the construction of a new object, or when the periods of closing the road to traffic must be extremely short, which necessitates leaving the supports where they are. By relieving the cap beams and piers and improving their operation, the presented structural modifications of typical solutions may in many cases enable thus outlined scope of repairs.

\section{References}

1. PN-64/B-02015:1966: Bridges, viaducts and culverts. Loads and impacts

2. PN-85/S-10030:1985: Bridges. Loads 